\title{
Analysis of avalanche risk factors in backcountry terrain based on usage frequency and accident data in Switzerland
}

\author{
F. Techel, B. Zweifel, and K. Winkler \\ WSL Institute for Snow and Avalanche Research SLF, 7260 Davos, Switzerland \\ Correspondence to: F. Techel (techel@slf.ch)
}

Received: 28 July 2014 - Published in Nat. Hazards Earth Syst. Sci. Discuss.: 13 August 2014

Revised: 15 July 2015 - Accepted: 19 August 2015 - Published: 9 September 2015

\begin{abstract}
Recreational activities in snow-covered mountainous terrain in the backcountry account for the vast majority of avalanche accidents. Studies analyzing avalanche risk mostly rely on accident statistics without considering exposure (or the elements at risk), i.e., how many, when and where people are recreating, as data on recreational activity in the winter mountains are scarce. To fill this gap, we explored volunteered geographic information on two social media mountaineering websites - bergportal.ch and camptocamp.org. Based on these data, we present a spatiotemporal pattern of winter backcountry touring activity in the Swiss Alps and compare this with accident statistics. Geographically, activity was concentrated in Alpine regions relatively close to the main Swiss population centers in the west and north. In contrast, accidents occurred equally often in the less-frequented inner-alpine regions. Weekends, weather and avalanche conditions influenced the number of recreationists, while the odds to be involved in a severe avalanche accident did not depend on weekends or weather conditions. However, the likelihood of being involved in an accident increased with increasing avalanche danger level, but also with a more unfavorable snowpack containing persistent weak layers (also referred to as an old snow problem). In fact, the most critical situation for backcountry recreationists and professionals occurred on days and in regions when both the avalanche danger was critical and when the snowpack contained persistent weak layers. The frequently occurring geographical pattern of a more unfavorable snowpack structure also explains the relatively high proportion of accidents in the lessfrequented inner-alpine regions. These results have practical implications: avalanche forecasters should clearly communicate the avalanche danger and the avalanche problem to the backcountry user, particularly if persistent weak layers are of
\end{abstract}

concern. Professionals and recreationists, on the other hand, require the expertise to adjust the planning of a tour and their backcountry travel behavior depending on the avalanche danger and the avalanche problem.

\section{Introduction}

Winter sports activities in mountainous terrain - such as ski, snowboard or snowshoe touring - have become increasingly popular during recent decades (Lamprecht et al., 2008, 2014; Winkler, 2015). One of the greatest hazards to winter sport recreationists and professionals ${ }^{1}$ in snow-covered mountainous terrain are avalanches. While avalanche accidents are relatively rare, they often have severe consequences leading to injury, or even death.

Avalanche accident studies show - for instance, for countries in the European Alps - that the vast majority of avalanche accidents involving people occurred during winter sports activities in uncontrolled terrain with recreationists triggering the avalanche in most cases themselves (e.g. Valt, 2009; Jarry, 2011; Techel and Zweifel, 2013). Investigations of such human-triggered avalanches have shown that typical snowpack patterns exist. Often these accidental avalanches failed in so-called "persistent" weak layers - snow layers that were either coarse-grained, soft and had undergone temperature-gradient metamorphism or consisted of buried surface hoar (Jamieson and Geldsetzer, 1999; Schweizer and Lütschg, 2001). Based on these findings, Schweizer and Jamieson (2007) developed a field test helping recreationists

\footnotetext{
${ }^{1}$ hereafter we refer to recreationists meaning recreationists and professionals
} 
and professionals to detect unfavorable snowpack layers or interfaces relevant for skier triggering.

Harvey and Signorell (2002) investigated snow and meteorological conditions on days with accidental avalanches. Later, Harvey (2008) introduced four avalanche problems (in Switzerland called "Muster" = patterns, described in detail in Harvey et al., 2012) using the fact that humans recognize recurring patterns of snow and avalanche situations based on few key observations more easily. The avalanche problems have become part of the avalanche education in Switzerland, but were also introduced in the avalanche forecast (e.g. in the Swiss avalanche bulletin, SLF, 2014). In contrast to the avalanche danger level, which describes "How high is the avalanche danger?" the avalanche problem addresses the question "What is the (avalanche) problem?" (Harvey et al., 2012; SLF, 2014). The avalanche problem related to the persistent weak layer problem is the "old snow" problem.

Knowledge on avalanche formation and recurring patterns of avalanche accidents resulted in the development of rulebased decision frameworks allowing recreationists to assess the avalanche risk based on some key criteria like avalanche danger level, slope angle or slope aspect (e.g. Munter, 1992, 1997; Engler and Mersch, 2001) or field observations (McCammon, 2006). As McCammon and Hägeli (2007) have shown, all these frameworks have the potential to reduce the majority of accidents. However, due to the lack of backcountry usage data, these studies were limited to the number of accidents and thus did not calculate risk.

While data collection methods concerning avalanche accidents are often well established, it is considerably more challenging to collect data on backcountry usage. Recently, usage data were collected exploring heli-ski or national park registration logbooks (Grímsdóttir and McClung, 2006; Moss, 2009), by counting users at start and end locations of tours (Procter et al., 2013), light barriers or by voluntary selfregistration boards (Zweifel et al., 2006). Common to all these studies is their limitation to either certain user-groups (like heli-skiers, Grímsdóttir and McClung, 2006) and/or in space (like a small number of start- or end-points of tours, Zweifel et al., 2006) and/or time (few observation days, Procter et al., 2013). Despite their limitations, these studies confirmed the influence of risk factors like slope angle, avalanche danger or snow stability.

Recently, web portals designed to share information on current mountaineering conditions have become increasingly popular. Social media websites specifically targeting recreationists like backcountry skiers and mountaineers - as bergportal.ch and camptocamp.org - allow any internet user to post and view reports on mountaineering, snow and skiing conditions at a certain day and location. Volunteered geographic information (VGI, Goodchild, 2007) has been analyzed for other social media websites showing interesting possibilities - for instance for disaster management or dynamics of human mobility (Poser and Dransch, 2010; Sagl et al., 2012) - but also limitations - for instance the accuracy of geolocation (e.g. Goodchild and Li, 2012) or a larger share of urban compared to rural social media users (e.g. Grossenbacher, 2014).

\section{Problem statement and research questions}

Focusing on avalanche accidents in Switzerland, statistics show that 236 people lost their lives in 179 avalanche accidents during the winter months December to April in the 20 years between 1994/95 and 2013/14 while backcountry touring $^{2}$ (Fig. 1). Almost $70 \%$ of these avalanche accidents occurred in the cantons Valais (VS) and Grisons (GR), despite these two cantons covering only $61 \%$ of the Swiss Alpine area above $1500 \mathrm{~m}$. The reasons for the relatively increased frequency of accidents in the cantons VS and GR are unknown, but may be manifold. Answering questions like "Is the touring terrain more challenging or are there simply more recreationists in backcountry terrain in the cantons VS and GR? Is the avalanche danger more often higher or is the snowpack structure more often unfavorable in these regions?" may shed some light on this regional inequality.

To answer these questions, it is necessary to know when and where users recreate in Switzerland. However, there is currently no data describing spatiotemporal patterns of winter backcountry usage in the Swiss Alps. To fill this gap, we explored volunteered geographic information posted on the two social-media mountaineering networks bergportal.ch and camptocamp.org. In a second step, we used this information to investigate relevant conditions causing a higher backcountry avalanche risk.

With this study, we address the following questions:

- Does volunteered geographic information posted on social media mountaineering sites provide a plausible spatiotemporal picture of winter backcountry usage in Switzerland?

- Which weather, snowpack and avalanche conditions contribute to a higher risk to be involved in an avalanche accident in the backcountry?

\section{Data and methods}

Avalanche risk is defined as "the probability or chance of harm resulting from interactions between avalanche hazard and (a) specific element(s) at risk. Avalanche risk is determined by the exposure of that element, and its vulnerability to the avalanche hazard". (Statham, 2008, p.225) Therefore, data on avalanche accidents and backcountry touring activity $^{3}$ are required to calculate backcountry avalanche risk. In

\footnotetext{
2 data: Swiss avalanche accident database

3 touring is defined as ascending by its own means, thus excluding accidents close to or within ski areas (ascending with help of ski lift, gondola or train)
} 


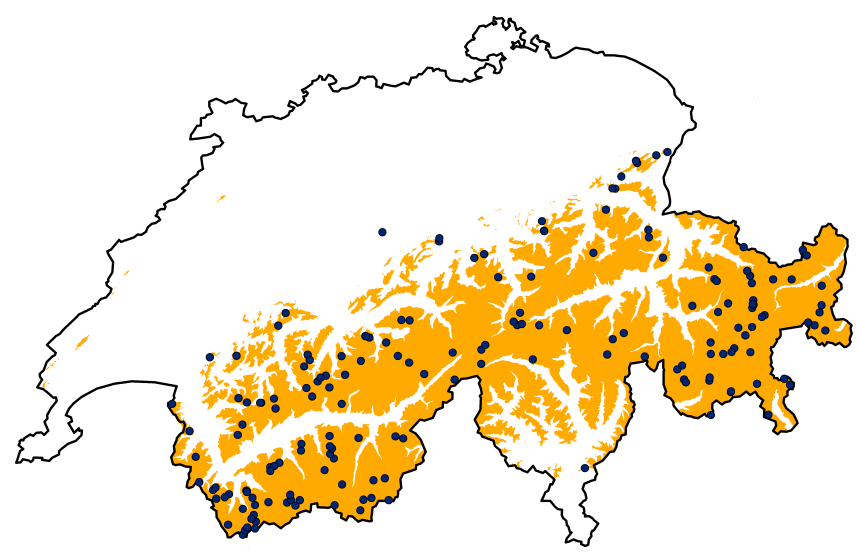

Figure 1. Map of Switzerland showing the geographical distribution of fatal avalanche accidents while backcountry touring during the winter months December to April for the 20 years 1994/952013/14 (blue points, data: Swiss avalanche accident database). The elevation range above $1500 \mathrm{~m}$ a.s.l., where more than $95 \%$ of the avalanche accidents occurred, is shaded orange. Map data: dhm $25{ }^{{ }^{\circ}} 2015$ swisstopo (5704 000000$)$, reproduced by permission of swisstopo (JA100118).

this study, we relied on Swiss data of severe avalanche accidents during winter backcountry touring in uncontrolled terrain and data from social mountaineering networks. Thus, we defined avalanche risk as the "risk of a backcountry recreationist to be involved in a severe avalanche accident". As we have no absolute numbers of backcountry recreationists, we investigate relative risk - relative between different conditions.

Following, we describe first the data and data preparation methods necessary to calculate avalanche risk: avalanche accidents and activity. For both, we analyzed the five winter months December-April from 2009/10 to 2013/14 for which we have data on accidents and activity available. Then we present the data used to investigate weather, snowpack and avalanche conditions (potential risk factors). Finally, we will describe the statistical methods used to analyze the data.

\subsection{Severe backcountry touring accidents}

We extracted avalanche accident data from the Swiss avalanche accident database. We defined avalanche accidents as severe if at least one person was fully buried, or injured or died in an accident. We excluded relatively harmless accidents as the reporting frequency is much lower and the reporting less consistent than for severe accidents. The latter are reported by rescue organizations, police, the SLF observers and the public throughout Switzerland in a formalized way and therefore they equally represent all regions in Switzerland (Techel and Zweifel, 2013). Further, to match the type of activity between the accidents and the usage data, we considered only accidents which occurred during back- country touring (the web-portals represent touring conditions see below).

179 severe avalanche accidents (hereafter accidents) occurred during the investigated time period, in which 354 people were caught. Sixty-one of these 179 avalanches resulted in 79 fatalities.

\subsection{Backcountry touring activity}

We explored the two social media mountaineering websites bergportal.ch and camptocamp.org. On these websites, any internet user can post their own or view other condition reports from mountain climbs, ski or snowshoe tours or other recreational activities. While the number of submitted reports reaches several thousand per winter in the Swiss Alps, these reports represent just a fraction of the real backcountry activity. However, hundreds of people view most reports and the total number of page views exceeds several hundred thousand per month (Bergportal, 2014).

To post a condition report, a user selects from an existing list the undertaken mountain summit and the route. If the summit or route is not yet on the list, he may add it to the guidebook. The community maintains the Wikipediastyle guidebooks. Most users describe the weather, snow and avalanche conditions encountered during the trip. Photos and, less frequently, movies and GPS-tracks are posted.

1476 Bergportal-users (German-spoken) posted 10479 geo-referenced reports, and 736 users reported 5107 tours on camptocamp (predominantly French and Italian). Generally, two people traveled together (median 2, mean 2.7). We focused on the date of the tour and location of the (intended) summit, as they are rather objective parameters. We analyzed only reports with summits exceeding an elevation of $1500 \mathrm{~m}$ a.s.l. as this is the elevation where most avalanche accidents occurred (see also Sect. 3.5). Additional information, like summit elevation, route difficulty, group size and other information were explored on a more descriptive level to describe the activity data set.

\subsection{Weather, avalanche danger and snowpack conditions}

We investigated different parameters that might potentially contribute to a higher relative risk to be involved in a severe avalanche accident. We focused on whether weekend-days or weekdays, weather, snowpack and avalanche conditions influence avalanche risk in the backcountry.

\subsubsection{Weather}

We used the modal value per region (regions are described in Sect. 3.4) of the manual morning weather observations from the SLF observer network (about 15000 manual observations per winter). Observations were classified using three categories (for frequencies refer to Table 1) 
Table 1. Overview of the data for the base rate of the weather, avalanche danger and snowpack conditions (e.g. the frequency a danger level was forecast), and the distribution of activity and accidents. Relative and absolute frequencies are shown.

\begin{tabular}{|c|c|c|c|c|}
\hline Variable & Level & Base rate & Accidents & Activity \\
\hline \multirow[t]{4}{*}{ Day of the week } & \multirow[t]{2}{*}{ weekend-day } & $28.6 \%$ & $56.4 \%$ & $56.1 \%$ \\
\hline & & 2 & 101 & 56101 \\
\hline & \multirow[t]{2}{*}{ week-day } & $71.4 \%$ & $43.6 \%$ & $43.9 \%$ \\
\hline & & 5 & 78 & 43899 \\
\hline \multirow[t]{6}{*}{ Weather } & \multirow[t]{2}{*}{ fine } & $58.0 \%$ & $77.1 \%$ & $80.8 \%$ \\
\hline & & 3069 & 138 & 80815 \\
\hline & \multirow[t]{2}{*}{ fair } & $19.2 \%$ & $10.6 \%$ & $9.4 \%$ \\
\hline & & 1017 & 19 & 9378 \\
\hline & \multirow[t]{2}{*}{ poor } & $22.8 \%$ & $12.3 \%$ & $9.8 \%$ \\
\hline & & 1206 & 22 & 9807 \\
\hline \multirow{8}{*}{$\begin{array}{l}\text { Avalanche danger } \\
\text { level }\end{array}$} & \multirow[t]{2}{*}{$1-$ Low } & $17.4 \%$ & $5.0 \%$ & $18.1 \%$ \\
\hline & & 15079 & 9 & 18072 \\
\hline & \multirow[t]{2}{*}{2 - Moderate } & $46.9 \%$ & $42.4 \%$ & $55.7 \%$ \\
\hline & & 40534 & 76 & 55685 \\
\hline & \multirow[t]{2}{*}{3 - Considerable } & $34.6 \%$ & $52.0 \%$ & $26.0 \%$ \\
\hline & & 30024 & 93 & 25982 \\
\hline & \multirow[t]{2}{*}{$4-$ High } & $1.1 \%$ & $0.6 \%$ & $0.26 \%$ \\
\hline & & 933 & 1 & 261 \\
\hline \multirow[t]{8}{*}{ Snowpack } & \multirow[t]{2}{*}{ A (favorable) } & $23.1 \%$ & $15.7 \%$ & $24.6 \%$ \\
\hline & & 19235 & 28 & 24307 \\
\hline & \multirow[t]{2}{*}{ B } & $25.6 \%$ & $27.0 \%$ & $26.5 \%$ \\
\hline & & 21336 & 48 & 26242 \\
\hline & \multirow[t]{2}{*}{$\mathrm{C}$} & $26.4 \%$ & $26.4 \%$ & $26.5 \%$ \\
\hline & & 21946 & 47 & 26215 \\
\hline & \multirow[t]{2}{*}{ D (unfavorable) } & $24.9 \%$ & $30.9 \%$ & $22.4 \%$ \\
\hline & & 20710 & 55 & 22182 \\
\hline
\end{tabular}

- 1 - fine: less than $50 \%$ cloudiness,

-2 - fair: if neither category 1 nor 3 ,

- 3 - poor: precipitation, storm, poor visibility (fog).

\subsubsection{Avalanche danger}

Avalanche danger describes the probability of an avalanche to occur and the destructive size of the avalanche (Statham, 2008; SLF, 2014). In Switzerland, the SLF forecasts the regional avalanche danger in the daily avalanche bulletins using the European five-level avalanche danger scale and complemented with a danger description. For our analysis, we extracted the avalanche danger level from the evening forecast of the Swiss avalanche bulletin - issued at 5 p.m. CET - and valid for the next day (the day of interpretation) until 5 p.m. (SLF, 2014; Table 1). Danger level 5 was not forecasted during this period.

\subsubsection{Snowpack structure and old snow avalanche problem}

We focused on the "old snow" avalanche problem for two reasons: (1) many avalanche accidents are associated to the failure of persistent weak layers, and (2) we suspect that the relatively larger proportion of avalanche accidents in the inner-alpine regions might be attributed to a more frequently unfavorable snowpack structure in these areas.

To reconstruct the regional snowpack structure we used the following three data sources, which are all part of the operational network used for avalanche forecasting in Switzerland.

- Manual snow profiles observed in potential avalanche slopes. The profiles were classified by the snowstructure classification in operational use in Switzerland (Techel and Pielmeier, 2014). For the purpose of this analysis, we considered very unfavorable and unfavorable profiles as unfavorable, the remainder as favorable. This resulted in $48 \%$ of the 3753 snow profile observations being classified as unfavorable.

- Rutschblock stability tests (RB; Föhn, 1987; Schweizer, 2002) observed on potential avalanche slopes. We classified RB results as unfavorable for tests which failed in persistent weak layers (weak layer criteria as defined by the threshold sum approach, Schweizer and Jamieson, 2007 ) with low or moderate load (RB score 1-4) or with moderate load and whole-block release (RB score 5). $12 \%$ of the $1747 \mathrm{RB}$ results were classified as unfavorable.

- The main avalanche problem (Harvey et al., 2012; SLF, 2014), as evaluated by the specifically trained, professional mountain guides (mAvalanche network; Suter et al., 2010). We considered the avalanche problem as unfavorable for days when the guides indicated the old snow avalanche problem as a primary avalanche problem on days with a critical avalanche danger situation (danger level $\geq 3$ for dry snow avalanches). Of the 5899 assessments, $12 \%$ were classified as unfavorable.

As described above, each of the observations was classified as favorable or unfavorable in the sense of an old snow problem. With snowpack observations being more scarce than weather observations or avalanche danger forecasts (both available daily and for each region), we used the ratio of unfavorable to favorable observations for each half-month period in each of the four main regions (regionalization Sect. 3.4). Profiles were relatively more frequently classified as unfavorable $(48 \%)$ than the RB test and avalanche problem $(12 \%)$. As this could potentially introduce a bias depending on the proportion of profiles in each time interval, we calculated the ratio unfavorable to favorable observations for the two observations sources separately (profiles by themselves, RB tests and avalanche problem together). Then, we added these half-month regional ratios and rank-ordered them from the most favorable to the most unfavorable. We assigned four classes with A being the most favorable $25 \%$ of the data and D being the most unfavorable $25 \%$ of the data. The regional snowpack structure value is thus a dimensionless, relative index and not an absolute value. A-periods had less than $12 \%$ unfavorable observations, while D had 
more than $35 \%$ unfavorable observations. We use the following terminology for the snowpack classes: unfavorable $(D)$, rather unfavorable $(C+D)$, rather favorable $(A+B)$, favorable (A).

\subsection{Regionalization}

Activities (summit coordinates), accidents (starting zone coordinates), weather and snowpack observations and the avalanche forecast were intersected with the more than 120 forecast-areas used to regionalize the avalanche forecast (Stoffel and Meister, 2004).

For the purpose of this analysis, we split the territory of the Swiss Alps into 15 snow-climatological regions (Fig. 2) based on the snow and avalanche climatology classification (Laternser, 2002) and an avalanche forecaster's perspective (Harvey and Zweifel, 2008). Snowpack patterns were explored on a larger scale using only four regions (N: N1-N5, VS: VS1-VS5, GR: GR1-GR5 and S: S1, Fig. 2).

\subsection{Alpine terrain}

Avalanches which caused fatalities had a mean starting zone elevation of $2497 \mathrm{~m}$ with $95 \%$ of the starting zones lying within $1495 \mathrm{~m}$ and $3502 \mathrm{~m}$ a.s.l. (winters 1994/95 to 2013/14, months December to April, activity: backcountry touring; data source: Swiss avalanche accident database). In approximation, we considered the elevation range above $1500 \mathrm{~m}$ a.s.l. as the elevation range most relevant for avalanches (Fig. 1). Using a digital elevation model (map data: swisstopo, 2015) we calculated the surface area above $1500 \mathrm{~m}$ a.s.l. for the 15 regions to investigate the densities of accidents and recreationists per surface area.

\subsection{Statistical methods for data analysis}

All social media platforms relying on users to generate content share the same problem: participation inequality (Nielsen, 2006). Most users do not contribute at all, while a small percentage of heavy submitters contribute the bulk of the content. Nielsen (2006) calls this the "90-9-1 rule" (90\% lurkers, $9 \%$ intermittent contributors, $1 \%$ heavy contributors). This applies also to our data set. Of the 2212 users posting reports, $1 \%$ posted $12 \%, 9 \%$ posted $41 \%, 90 \%$ posted $47 \%$ of the reports and an unknown, but presumably very large number did not contribute at all but consumed information only. Nielsen (2006), but also others, pointed out that participation inequality might bias this kind of data. Therefore, we stratified the data into the groups heavy contributors $\left(c_{\mathrm{h}}\right.$, top $\left.1 \%\right)$, frequent contributors $\left(c_{\mathrm{f}}\right.$, top $\left.2-10 \%\right)$ and rare contributors $\left(c_{\mathrm{r}}\right.$, remaining $90 \%$ of users). We then analyzed the data set in three steps:

1. The data were stratified by the three contributor groups $\left(c_{\mathrm{h}}, c_{\mathrm{f}}, c_{\mathrm{r}}\right)$ and tested for differences between each

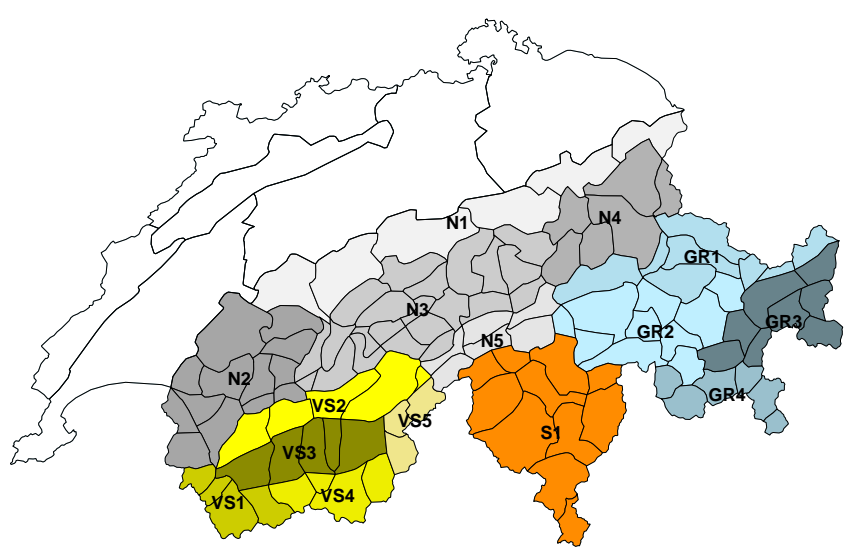

Figure 2. Map of Switzerland showing the forecast areas used to regionalize the avalanche bulletin (smaller polygons) and the 15 regions used for analysis in this paper (colored and labeled).

two strata using the Wilcoxon rank-sum test (Crawley, 2007) with an emphasis on spatiotemporal variations.

2. Based on the outcome of 1, we randomly selected 1000 data entries with the sampling probability equaling the proportion of users in each stratum (systematic stratified sampling, Tillé and Matei, 2012). As Tillé (2006) pointed out, it may often be desirable to sample with unequal inclusion probabilities if strata are different in size or characteristics. In our case, the stratified sample will give less weight to the most frequent contributors $c_{\mathrm{h}}$ and more to the rare contributors $c_{\mathrm{r}}$. Sampling was repeated 100 times.

3. We used the resulting sample as the most representative sample for further analysis.

Equality of proportions in $2 \times 2$ contingency tables (reference and observed frequencies) was tested using Fisher's exact test for count data (Boslaugh and Watters, 2008). An example for a $2 \times 2$ table with reference and observed frequencies is the frequency avalanche danger levels 2 and 3 were forecasted compared to the observed activity at these danger levels.

To estimate the odds of an outcome being more likely in certain conditions, the odds ratio $(\mathrm{OR})$ with median-unbiased estimate and the $95 \%$ confidence interval (CI) was calculated for the $2 \times 2$ tables (Aragon, 2012). The odds ratio, often used in case-control studies, is insensitive to the number of controls (Boslaugh and Watters, 2008). For this analysis, we treat the accident data like a subset of the activity (without an accident). For each of the analyzed parameters, we always compared two levels of conditions (a reference and a test level). For example, the OR between danger levels 2 (reference level) and 3 (test level) with accidents as case and 
activity as control was calculated as follows:

$\mathrm{OR}=\frac{\frac{\text { accidents }_{3}}{\text { activity }_{3}}}{\frac{\text { accidents }_{2}}{\text { activity }_{2}}}$.

Differences between two populations and odds ratios were considered significant if the level of significance was $p<0.05$.

\section{Results}

\subsection{Weather, avalanche danger and snowpack conditions}

The weather was fine on $58 \%$ of the days (Table 1) with more fine days in the VS regions $(66 \%)$ and less in the $\mathrm{N} 4$ region $(52 \%)$. Avalanche danger level 3 or higher was issued on $35 \%$ of the days with more days with a critical situation in the VS regions $(1,2,4,5)$ and region N5 (> 40\%) and less in the regions N1 and $\mathrm{S} 1(<30 \%)$. During the investigated 5-year period, the snowpack was most often rather unfavorable in the region GR (74\% of the days), followed by VS (49\%) and $\mathrm{N}$ (42\%, Table 2). Considering just the $70 \%$ of the periods for which there was data available for all regions, GR had the most unfavorable snowpack on $63 \%$ of the days. VS was generally more favorable than GR, but considerably more often unfavorable than the regions in the $\mathrm{N}$ or S $(71 \%$ of the days). At danger level 1 the snowpack was slightly more often rather favorable (54\%) than at the other danger levels (level 2: $48 \%$, level 3: $47 \%$ ).

\subsection{Avalanche accidents}

The number of avalanche accidents was highest in February $(31 \%)$, with the other months sharing similar proportions (16-19\%). The largest numbers (absolute values) of accidents were recorded on weekends $(56 \%)$, when the weather was fine $(77 \%)$, at danger level $3(52 \%)$, in rather unfavorable snowpack conditions (57\%, Table 1) and in the regions N2, N3, VS3 and GR 2 (Fig. 3a). Relative to the normal weather, snowpack and avalanche conditions (base rate values shown in Table 1), accidents were more frequent in fine weather (compared to poor weather, $p<0.001$ ), and increased from danger levels 1 to $2(p<0.001)$, and 2 to 3 $(p<0.001)$, while danger levels 3 and 4 showed similar proportions (Table 3 ). The number of accidents per surface area above $1500 \mathrm{~m}$ a.s.l. was well above the Swiss median in parts of the north and in the VS region, while it was considerably lower in the regions N4, VS5 and S1 (Fig. 3a). Accidents occurred more often during times and periods when the snowpack was unfavorable ( $p=0.01$, Table 3$)$. However, there are regional differences: in GR, where the snowpack was rather unfavorable during $74 \%$ of the time, $75 \%$ of the accidents occurred during these conditions (Table 2). In the $\mathrm{N}$ a relatively larger proportion of accidents occurred on days with a
Table 2. Frequencies for the snowpack classes rather favorable and rather unfavorable for the main regions. No data for region $\mathrm{S}$ are shown, as this region had rather incomplete data (data covering only $70 \%$ of the time) and rarely any accidents. Relative and absolute frequencies are given.

\begin{tabular}{lllll}
\hline Region & Snowpack & Base rate & Accidents & Activity \\
\hline $\mathrm{N}$ & A/B (rather favorable) & $58.2 \%$ & $46.3 \%$ & $59.4 \%$ \\
& & 22560 & 31 & 31653 \\
& C/D (rather unfavorable) & $41.8 \%$ & $53.7 \%$ & $40.6 \%$ \\
& & 16211 & 36 & 21618 \\
\hline VS & A/B (rather favorable) & $51.3 \%$ & $50 \%$ & $50.9 \%$ \\
& & 8011 & 26 & 11640 \\
& C/D (rather unfavorable) & $48.7 \%$ & $50 \%$ & $49.1 \%$ \\
& & 7601 & 26 & 11232 \\
\hline GR & A/B (rather favorable) & $26.4 \%$ & $25.4 \%$ & $26.1 \%$ \\
& & 6116 & 13 & 5105 \\
& C/D (rather unfavorable) & $73.6 \%$ & $74.5 \%$ & $73.9 \%$ \\
& & 17034 & 38 & 14480 \\
\hline
\end{tabular}

Table 3. $p$ values for the Fisher exact test testing equality of proportions of the expected and observed frequencies as shown in Table 1 (base rate vs. rate of accidents or activity). $p$ values $\leq 0.05$ are shown in bold.

\begin{tabular}{lllll}
\hline & Variable & $\begin{array}{l}\text { Reference } \\
\text { level }\end{array}$ & $\begin{array}{l}\text { Test } \\
\text { level }\end{array}$ & $p$ value \\
\hline \multirow{2}{*}{ Accidents } & Weather & fine & poor & $\mathbf{1 0}^{-\mathbf{1 3}}$ \\
& Avalanche danger level & 1 & 2 & $\mathbf{1 0}^{-\mathbf{1 2}}$ \\
& & 2 & 3 & $\mathbf{1 0}^{-\mathbf{7}}$ \\
& Snowpack & 3 & 4 & 0.14 \\
\multirow{2}{*}{ Activity } & Weather & A & D & $\mathbf{0 . 0 1}$ \\
& Avalanche danger level & C/D & 0.32 \\
& & fine & poor & $\mathbf{1 0}-\mathbf{2 0}$ \\
& & 2 & 2 & 0.29 \\
& Snowpack & 3 & 3 & $\mathbf{1 0}$ \\
& & A & D & 0.16 \\
& & A/B & C/D & $\mathbf{1 0}^{-\mathbf{2 3}}$ \\
\hline
\end{tabular}

rather unfavorable snowpack ( $54 \%$ of the accidents on $42 \%$ of the days).

\subsection{Winter backcountry activity based on volunteered geographic information}

Reported activity was high between mid-December and the beginning of April (85\% of posts). Towards spring, particularly in April, activity shifted further south and west (the largest proportion of high alpine mountains lies in the western part of Switzerland) compared to the other months (coordinates, $p<0.05$ ). Geographically, the highest activity (absolute values) was recorded in the regions $\mathrm{N} 2$ and $\mathrm{N} 3$ $(36 \%)$ with considerably less activity in other regions, as for instance VS (VS1-VS5: $22 \%$ ) or GR (GR1-GR4: 19\%). There were no geographical differences between weekenddays and weekdays. 

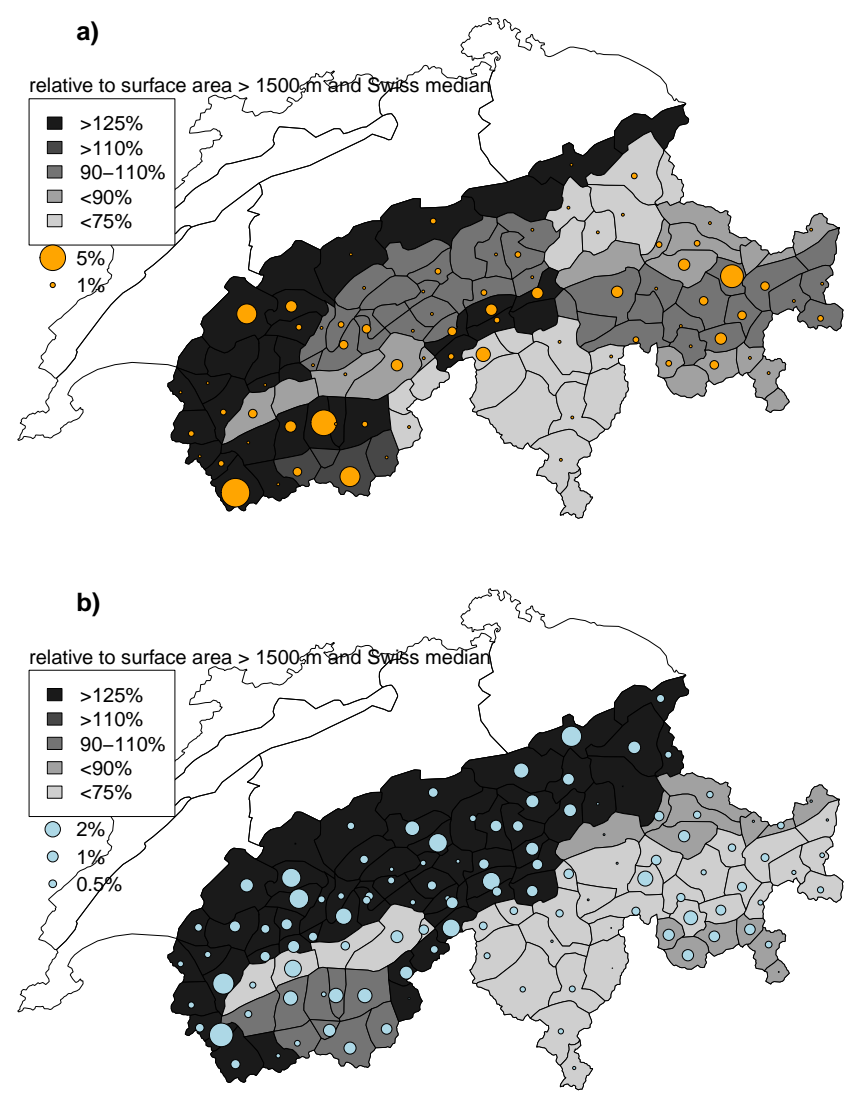

Figure 3. Geographical distribution of (a) severe avalanche accidents and (b) backcountry touring activity in Switzerland. The size of the circles indicates the relative proportion of all accidents or activities, respectively. The background color indicates the number of accidents (or activities) in relation to the surface area above $1500 \mathrm{~m}$ a.s.l. and is standardized by the median across all regions.

On Bergportal (German-spoken) more tours were undertaken in the north and east than on camptocamp (French and Italian, $p<0.001)$. This geographical distribution mirrors the main three Swiss language regions (German in the north and east, French and Italian in the west and south). The proportion of French and Italian posts (camptocamp) was almost identical to the proportion of French and Italian speakers in Switzerland (33 vs. $31 \%$, Bundesamt für Statistik, 2013). The proportion of routes graded harder than WS (wenig schwierig = "slightly difficult") showed minor differences between the two web-portals (bergportal 35\%, camptocamp $32 \%$ ).

Heavy web-portal contributors $\left(c_{\mathrm{h}}\right.$, refer to Sect. 3.6 for details) undertook tours considerably more often in the northwestern part of the Swiss Alps than the groups frequent $\left(c_{\mathrm{f}}\right)$ and rare contributors $\left(c_{\mathrm{r}}\right.$, summit coordinates, $\left.p<0.001\right)$. This shows most pronounced in the number of posts by region with $54 \%$ of $c_{\mathrm{h}}$ tours in N2-N3, compared to $34 \%$ for $c_{\mathrm{f}}$ and $c_{\mathrm{r}}$. The summit coordinates for $c_{\mathrm{f}}$ and $c_{\mathrm{r}}$ were similar, but $c_{\mathrm{r}}$ undertook ski tours more often at lower danger levels than $c_{\mathrm{h}}$ and $c_{\mathrm{f}}(p<0.01)$. These results underline the geographical bias introduced by the heavy contributors. Thus, as outlined in Sect. 3.6, we use the stratified sample with the strata being the three contributor classes for the remainder of this study.

Activity (absolute values) was greatest on weekends $(56 \%)$ when the weather was fine $(81 \%)$ and when the avalanche danger level was $2(56 \%$, Table 1$)$. The activity per surface area above $1500 \mathrm{~m}$ a.s.l. was well above the overall median for most regions in the north and in parts of VS, while it was considerably below in the central parts of GR (GR2, GR3), VS2 and S1 (Fig. 3b). Compared to the normal weather, snowpack and avalanche conditions (base rate as shown in Table 1), users went considerably more often on a tour on weekend-days and when the weather was fine $(p<0.001$, Table 3$)$. If avalanche danger level 3 was forecasted, activity was strongly reduced (OR 0.63 , CI 0.52 $0.77, p<0.001)$. There was also less activity during periods with a rather unfavorable snowpack ( $p=0.02$, Table 3 ). However, this is an artefact of the geographical distribution of activity with greater activity in the generally more favorable regions. Comparing activity and snowpack conditions for each region independently (Table 2), frequencies were similar $(p>0.05)$.

Generally, summits with higher elevation were the goal on days with fine weather and a lower avalanche danger. The number of aborted trips increased with an increase in avalanche danger (level 1: $4 \%$ to level 4: $32 \%$ ), a decrease in weather conditions (fine weather $7 \%$ to poor weather $15 \%$ ) and an increase in route difficulty. The proportion of routes with grades harder than grade WS decreased with increasing avalanche danger (level 1: $50 \%$ to level 3: $17 \%$ ). N1 had the lowest proportion of routes harder than WS (12\%), followed by the three inner-alpine regions (GR3, VS3, GR2: 21-25\%) and N3, GR4 and VS1 had the highest share of difficult routes $(\geq 40 \%)$.

\subsection{Factors contributing to a higher risk of involvement in an avalanche accident}

The temporal distribution (in the season and during the week) and the weather conditions were similar for activities and accidents. For accident data, these results correspond well to previous research in other Alpine countries (e.g. Valt, 2009 for Italy and Pfeifer, 2009 for Tyrol/Austria). Thus, the relative risk of a backcountry user to be involved in an accident does not depend on weather conditions or the day of the week.

However, our results confirmed the well-known fact that avalanche danger is a risk factor. The odds of being involved in an avalanche accident increased from avalanche danger level 1 to 2 (OR: 2.75, $p<0.001$ ), and again from danger level 2 to 3 (OR: 2.62, $p<0.001$ ) resulting in a total increase in the OR from danger level 1 to 3 of 7.2 (Table 4). These odds ratios are slightly higher than factors estimated in 
previous studies, which did not use backcountry usage (e.g. Munter, 1997; Harvey, 2002, 2008) and may be attributed to the comparably reduced activity at danger level 3 .

A second factor contributing to higher risk in backcountry terrain is the snowpack (old snow problem, persistent weak layers). The odds for a severe avalanche accident to occur doubled during periods and in regions with an unfavorable snowpack compared to those with a favorable snowpack (OR $2.15, p<0.001$, Table 4). However, it is of note that regional differences occur. In GR, the region where the snowpack was most often unfavorable, there was no increase in the odds of an accident to occur in more unfavorable snowpack conditions. In contrast, in the region in the north $54 \%$ of the accidents occurred during periods with rather unfavorable snowpack conditions ( $42 \%$ of the days with $41 \%$ of the activity, Table 2; OR: 1.70, CI: $1.05-2.77, p=0.03$ ). For the often favorable region $\mathrm{S}$, the snowpack information was less complete (only $70 \%$ of the time) and the number of accidents extremely small. Therefore, we cannot draw any conclusions for this region. At danger level 3, the odds almost doubled from a favorable to an unfavorable snowpack (OR: 1.98, CI: $1.09-3.81, p=0.03$ ). Comparing the ratio accidents to activities for each of the four large regions, we note that the ratio is between 1.6 and 2 times higher in GR, VS and S compared to the N. On a smaller scale, the ratio was well above the Swiss median in the three inner-alpine regions GR3, VS3 und GR2 (Fig. 4). In fact, the ratios were 3-16 times higher than in the region N1, N4 and VS5, where the ratios were lowest. A closer comparison between these regions shows that in the inner-alpine regions the elevation of the summits was higher $(p<0.001)$, the weather conditions more often fine $(p<0.001)$, the snowpack more often unfavorable (68 vs. $44 \%, p<0.001)$ and the avalanche danger slightly more often at danger level 3 (36 vs. $31 \%$, not significant, $p>0.05$ ). A very prominent difference between these regions was the frequency days with the most critical combination - a rather pronounced old snow problem and danger level 3 - occurred. These were 1.6 times more often in the inner-alpine regions than in the other three regions.

In summary, the odds of being involved in a severe avalanche accident increased markedly with avalanche danger, but were also dependent on the severity of the old snow problem.

\section{Discussion}

\subsection{Chances and limitations of VGI as a data source for spatiotemporal characterization of backcountry usage}

We investigated volunteered spatiotemporal information from two social mountaineering networks. As Nielsen (2006) pointed out, social networks generally suffer from participation inequality potentially leading to a picture not repre-
Table 4. Odds ratios for the comparison between activity (expected frequencies) and accident data (observed frequencies). Given are the odds ratio (OR), the $95 \%$ confidence interval (CI) and the $p$ value (Fisher exact test).

\begin{tabular}{lllll}
\hline Variable & $\begin{array}{l}\text { Reference } \\
\text { level }\end{array}$ & $\begin{array}{l}\text { Test } \\
\text { level }\end{array}$ & OR $(95 \% \mathrm{CI})$ & $p$ value \\
\hline Weather & fine & poor & $1.31(0.99-1.74)$ & 0.06 \\
\hline Avalanche danger & 1 & 2 & $2.75(1.97-3.89)$ & $\mathbf{1 0}^{-\mathbf{1 0}}$ \\
& 1 & 3 & $7.21(5.13-10.29)$ & $\mathbf{1 0}^{-\mathbf{3 4}}$ \\
& 1 & 4 & $10.23(2.20-79.2)$ & $\mathbf{0 . 0 0 2}^{-23}$ \\
& 2 & 3 & $2.62(2.16-3.19)$ & $\mathbf{1 0}^{-\mathbf{2 3}}$ \\
& 3 & 4 & $0.98(0.25-4.93)$ & 1 \\
\hline Snowpack & $\mathrm{A}$ & $\mathrm{D}$ & $2.15(1.37-3.44)$ & $\mathbf{1 0}^{-\mathbf{3}}$ \\
& $\mathrm{A} / \mathrm{B}$ & $\mathrm{C} / \mathrm{D}$ & $1.40(1.04-1.89)$ & $\mathbf{0 . 0 3}$ \\
\hline
\end{tabular}

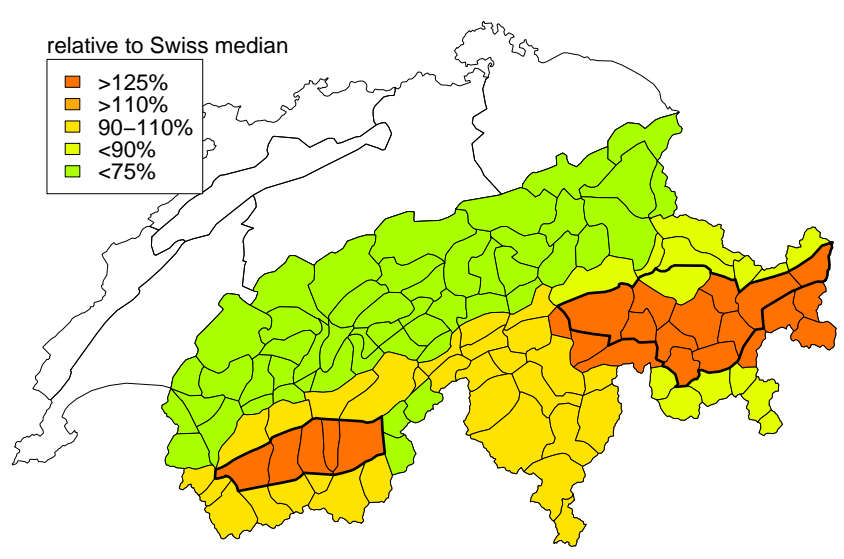

Figure 4. The map shows the ratio of accidents to activity for each region, relative to the Swiss median. The ratio was highest in regions VS2, GR2 and GR3, which are almost identical with the regions defined as the inner-alpine regions (bold black lines; SLF, 2014) in the avalanche bulletin.

sentative of the entire population; while credibility and data quality might be additional limitations of VGI (Flanagin and Metzger, 2008). By applying stratified sampling, we reduced the geographical bias introduced by the heavy contributors. However, a more detailed validation of the representativeness of the data is very challenging due to the lack of comparable studies. If representative, we would expect similar results in this paper and in previous studies that relied on actual counting of backcountry recreationists. One of the few previous studies available (Zweifel et al., 2006) confirmed the correlation between backcountry activity and fine weather conditions. Zweifel et al. (2006)'s study showed that the number of recreationists undertaking tours in the region of Davos (GR2) was 1.9 times higher on days with danger level 2 than 3 . This result was similar to our study with a ratio of 2.0 for the region of Davos and a ratio of 2.14 for all of the Swiss Alps (Table 1). However, differences existed in the distribution of weekdays and weekend-days. In Zweifel et al. (2006)'s study, the average daily number of recreationists was very 
similar throughout the week, while in this study the average daily number was 2.3 times higher on weekend-days compared to weekdays (region of Davos) and even 3.2 times higher for the full data set. We suspect that this difference was caused by the fact that web-portal contributors live relatively more often outside of the Swiss Alps, where the main Swiss population centers are located, and are able to undertake tours mostly on weekend-days rather than during the workweek. Several researchers (e.g. Grossenbacher, 2014; Hecht and Stephens, 2014) noted a similar pattern with rural areas having a proportionally smaller share of posts on social media than urban regions. These points highlight the importance of evaluating the geographical representativeness of the backcountry activity data. To our knowledge, there is only one study (Winkler and Techel, 2014) investigating the spatial distribution of backcountry users in Switzerland. In a survey concerning the Swiss avalanche bulletin, the authors also asked survey participants: "Where do you recreate mostly?" With two exceptions, there was a nearly perfect agreement between their data and our study (Appendix A, Table A1). Exceptions were the northern and central parts in GR, where the SLF is located, where considerably more survey participants recreated, while in the eastern parts of VS considerably fewer participants recreated. A plausible explanation for the discrepancy in the GR region might be that survey participation was relatively higher in the region of Davos (near the location of the avalanche institute). For the eastern VS, a sparsely populated region with interesting touring terrain, we suspect that backcountry users not living in this area recreate mostly in their local region but travel also relatively often to the eastern VS to undertake tours and subsequently post reports, compared to relatively few who mostly recreate in this region. As the proportion of recreationists is highly similar in both studies in the other regions, and due to a lack of additional data on the geographical distribution of backcountry users in Switzerland, we assume that the volunteered spatiotemporal information submitted on bergportal.ch and camptocamp.org provides a reasonably representative picture of backcountry touring activity. However, we are aware that both studies represent only a fraction of the backcountry recreationists and their activity. Also, we cannot exclude that both studies suffer a similar geographical bias towards a stronger representation of urban recreationists.

\subsection{Practical implications}

As the results have shown, an increase in avalanche danger and an unfavorable snowpack structure (old snow avalanche problem) increased the risk for backcountry recreationists and professionals to become involved in a severe avalanche accident. However, the risk was highest if the combination of an increased avalanche danger (danger level 3) and an unfavorable snowpack structure occurred at the same time.

A reason might be that a critical situation purely due to new snow or fresh snowdrift accumulations is relatively easy to recognize and mitigate, while situations with weak layers embedded deep in the old snow are considerably harder to detect - even by professionals (Schweizer and Lütschg, 2001). Additionally, avalanches failing in the old snow are often larger and therefore more dangerous than avalanches where the weakness is in the new snow (Techel and Winkler, 2015).

These results have practical implications for educating backcountry recreationists as well as for avalanche forecasting services. We recommend that avalanche forecasters describe clearly the regions with a pronounced old snow problem and provide the recreationist with precise and understandable information on the type of avalanche problem. Upto-date information about regional snowpack structure patterns is a pre-requisite for this. The backcountry recreationist, on the other hand, requires the knowledge to interpret these recommendations. Therefore, even greater emphasis should be given on educating recreationists on how to recognize and mitigate an old snow problem. Consequently, recreationists should consider not only the avalanche danger level, but also the avalanche problem when planning and undertaking a tour. This is particularly important if the danger level is 3 or higher and an old snow avalanche problem exists. In addition, avalanche-warning services should increase their efforts to reach recreationists prior to fine weather weekends and holidays to increase the awareness of the current avalanche danger and avalanche problem.

\section{Conclusions}

In recent years, there has been a large increase in volunteered geographic information (VGI) on the internet. We made use of this trend and investigated the spatiotemporal information (date and summit location) of condition reports posted on the two social media mountaineering web-portals bergportal.ch and camptocamp.org. This allowed us, for the first time, to explore the spatiotemporal distribution of winter backcountry touring activity in the Swiss Alps. In a second step, we compared the backcountry activity with avalanche accident data and could thus assess the relative risk of backcountry users to be involved in a severe avalanche accident in different weather, avalanche and snowpack conditions. By reducing the geographical bias introduced by the most frequent web-portal contributors, we could create a plausible spatiotemporal picture of backcountry usage for the Swiss Alps.

Activity was highest on weekends, when the weather was fine and the avalanche danger level relatively favorable (danger levels 1 or 2). Geographically, activity was concentrated relatively close to the main Swiss population centers in the north and west. The influence of weekends, weather conditions and the avalanche danger level on the number of backcountry recreationists likely reflects the fact that these are key criteria in the planning phase of a tour. However, there was 
no clear influence of the severity of the old snow problem on the activity. Similar to the activity patterns, the absolute frequency of avalanche accidents peaked on weekends and on days with fine weather. The likelihood to be involved in a severe avalanche accident increased considerably with increasing avalanche danger, but also with a more severe old snow problem. This showed on a regional scale, with the ratio of accidents to activities being highest in the inner-alpine regions where frequently unfavorable snowpack conditions prevail. However, during periods with a more pronounced old snow problem there were also significantly more accidents in the often-favorable snowpack region in the north.
Although we have presented a plausible pattern of the spatiotemporal distribution of recreationists, we recommend that future research should attempt to determine the absolute backcountry user numbers and to verify their regional distribution allowing for a better estimation of backcountry usage and the calculation of absolute avalanche risk. 


\section{Appendix A}

Table A1. Unpublished data (with permission from Kurt Winkler) from a survey concerning the avalanche bulletin (Winkler and Techel, 2014) and the corresponding values from this study.

\begin{tabular}{lclc}
\hline $\begin{array}{l}\text { Regions } \\
\text { (Winkler and Techel, 2014) }\end{array}$ & $\begin{array}{c}\text { "Where do recreationists } \\
\text { recreate mostly?" }\end{array}$ & $\begin{array}{l}\text { Winkler and Techel (2014)'s regions } \\
\text { are equivalent to the following } \\
\text { regions in this study }\end{array}$ & $\begin{array}{c}\text { Activity } \\
\text { this study }\end{array}$ \\
\hline N - western and central parts & $41 \%$ & N2, N3, parts of N1, N4, N5 & $42 \%$ \\
N - eastern parts & $11 \%$ & N4, parts of N1 & $9 \%$ \\
VS - western parts (French-spoken) & $13 \%$ & VS1, parts of VS2, VS3, VS4 & $12 \%$ \\
VS - eastern parts (German-spoken) & $4 \%$ & VS5, parts of VS2, VS3, VS4, N5 & $13 \%$ \\
GR - northern and central parts & $19 \%$ & GR2, most parts of GR1, parts of N5 & $14 \%$ \\
GR - southern parts & $7 \%$ & GR3, most parts of GR4, parts of GR1 & $7 \%$ \\
S & $5 \%$ & S1 & $4 \%$ \\
\hline
\end{tabular}


Acknowledgements. We thank Bergportal GmbH (in particular Reto Baur) and camptocamp (creative commons licence CC-by-sa (Camptocamp, 2014) with special permission to use CC-by-nc-nd content) for the permission to use their data. Also, we thank the rescue organizations Rettungsflugwacht Rega, Kantonale Walliser Rettungsorganisation KWRO-OCVS, Air Glaciers, and Air Zermatt and all the numerous SLF observers and employees, avalanche rescuers and backcountry recreationists who reported and collected accident data. Two anonymous reviewers, Stephan Harvey, Christine Pielmeier and Jürg Schweizer provided very helpful comments which greatly improved this work. Andreas Stoffel provided a helping hand with the GIS data.

Edited by: T. Glade

Reviewed by: two anonymous referees

\section{References}

Aragon, T.: epitools: Epidemiology Tools, r package version 0.5-7, available at: http://CRAN.R-project.org/package=epitools, last access: 5 June 2015, 2012.

Bergportal: Portrait and Media Data 2014, available at: https://www.bergportal.ch/data/documents/bergportal-ch_ mediadaten_englisch.pdf, last access: 24 June 2014, 2014.

Boslaugh, S. and Watters, P.: Statistics in a nutshell. A desktop quick reference, O'Reilly Media, Inc., Sebastopol, 1st Edn., 2008.

Bundesamt für Statistik: Sprachen, Religionen: Daten, Indikatoren. Strukturerhebung 2013, available at: http://www.bfs.admin.ch/ bfs/portal/de/index/themen/01/05/blank/key/sprachen.html,last access: 15 June 2015, 2013.

Camptocamp: License of the contents, available at: http://www. camptocamp.org/articles/106728/en/license-of-the-contents (last access: 22 July 2014), 2014.

Crawley, M.: The R book, John Wiley \& Sons Ltd., The Atrium, Southern Gate, Chichester, West Sussex PO19 8SQ, England, 1st Edn., 2007.

Engler, M. and Mersch, J.: Die weisse Gefahr - Schnee und Lawinen, Verlag Martin Engler, Rettenberg - Freidorf, 304 pp., 2001.

Flanagin, A. and Metzger, M.: The credibility of volunteered geographic information, GeoJournal, 72, 137-148, 2008.

Föhn, P.: The rutschblock as a practical tool for slope stability evaluation, IAHS Publ., 162, 223-228, 1987.

Goodchild, M.: Citizens as sensors: the world of volunteered geography, GeoJournal, 69, 211-221, 2007.

Goodchild, M. and Li, L.: Assuring the quality of volunteered geographic information, Spatial Statistics, 1, 110-120, 2012.

Grímsdóttir, H. and McClung, D.: Avalanche risk during backcountry skiing - An analysis of risk factors, Nat. Hazards, 39, 127$153,2006$.

Grossenbacher, T.: Studying human mobility through geotagged social media content, Master's thesis, University of Zürich, Geocomputation Unit (GIScience), Department of Geography, Zurich, 2014.

Harvey, S.: Avalanche incidents in Switzerland in relation to the predicted danger degree, in: Proceedings International Snow Science Workshop 2002, Penticton, B.C., 2002.
Harvey, S.: Mustererkennung in der Lawinenkunde, Jahrbuch des Kuratoriums für Alpine Sicherheit, 08, 88-94, 2008.

Harvey, S. and Signorell, C.: Avalanche accidents in backcountry terrain of the Swiss Alps: New investigations of a 30 year database, in: Proceedings International Snow Science Workshop 2002, Penticton, B.C., 2002.

Harvey, S. and Zweifel, B.: New trends of recreational avalanche accidents in Switzerland, in: Proceedings International Snow Science Workshop 2008, Whistler, B.C., 9-15, 2008.

Harvey, S., Rhyner, H., and Schweizer, J.: Lawinenkunde, Bruckmann Verlag GmbH, München, 2012.

Hecht, B. and Stephens, M.: A Tale of Cities: Urban Biases in Volunteered Geographic Information, in: Proceedings International AAAI Conference on weblogs and social media, Menlo Park, CA, 2014.

Jamieson, B. and Geldsetzer, T.: Patterns in unexpected skiertriggered avalanches, Avalanche News, 58, 7-17, 1999.

Jarry, F.: 40 ans d'accidents d'avalanche ...40 ans de prévention, Neige et Avalanches, 135, 18-22, 2011.

Lamprecht, M., Fischer, A., and Stamm, H.: Sport Schweiz 2008: Das Sportverhalten der Schweizer Bevölkerung, Magglingen, Bundesamt für Sport BASPO, 2008.

Lamprecht, M., Fischer, A., and Stamm, H.: Sport Schweiz 2014: Das Sportverhalten der Schweizer Bevölkerung, Magglingen, Bundesamt für Sport BASPO, 2014.

Laternser, M.: Snow and avalanche climatology of Switzerland, Naturwissenschaften ETH Zürich, PhD thesis, Nr. 14493, 2002.

McCammon, I.: Obvious clues method: a user's guide, The Avalanche Review, 25, 8-9, 2006.

McCammon, I. and Hägeli, P.: An evaluation of rule-based decision tools for travel in avalanche terrain, Cold Reg. Sci. Technol., 47, 193-206, 2007.

Moss, G.: Avalanche hazard and visitor numbers - a study in Lochaber, Scotland, in: Proceedings International Snow Science Workshop, Davos, 628-632, 2009.

Munter, W.: Neue Lawinenkunde. Ein Leitfaden für die Praxis, SAC-Verlag, Bern, 2nd Edn., 1992.

Munter, W.: 3x3 Lawinen, Agentur Pohl und Schellhammer, Garmisch-Partenkirchen, 1st Edn., 1997.

Nielsen, J.: The 90-9-1 rule for participation inequality in social media and online communities, available at: http://www.nngroup. com/articles/participation-inequality/, last access: 15 June 2015, 2006.

Pfeifer, C.: On probabilities of avalanches triggered by alpine skiers. An empirically driven decision strategy for backcountry skiers based on these probabilities, Nat. Hazards, 48, 425-438, 2009.

Poser, K. and Dransch, D.: Volunteered geographic information for disaster management with application to rapid flood damage estimation, Geomatica, 64, 89-98, 2010.

Procter, E., Strapazzon, G., Dal Cappello, T., Castlunger, L., Staffler, H., and Brugger, H.: Adherence of backcountry winter recreationists to avalanche prevention and safety practices in northern Italy, Scand. J. Med. Sci. Sports, 24, 823-829, doi:10.1111/sms.12094, 2013.

Sagl, G., Resch, B., Hawelka, B., and Beinat, E.: From social sensor data to collective human behaviour patterns - analysing and visualising spatio-temporal dynamics in urban environments, in: GI Forum 2012: Geovizualisation, Society and Learning, Herbert 
Wichmann Verlag, VDE VERLAG GMBH, Berlin/Offenbach, 54-63, 2012.

Schweizer, J.: The rutschblock test - procedure and application in Switzerland, The Avalanche Review, 20, 14-15, 2002.

Schweizer, J. and Jamieson, B.: A threshold sum approach to stability evaluation of manual profiles, Cold Reg. Sci. Technol., 47, 50-59, 2007.

Schweizer, J. and Lütschg, M.: Characteristics of human-triggered avalanches, Cold Reg. Sci. Technol., 33, 147-162, 2001.

SLF: Avalanche Bulletins and other products. Interpretation Guide. Edition 2014, WSL Institute for Snow and Avalanche Research SLF, Davos, Switzerland, 13th Edn., 50 pp., 2014.

Statham, G.: Avalanche hazard, danger and risk - a practical explanation, in: Proceedings International Snow Science Workshop 2008, Whistler, Canada, 224-227, 2008.

Stoffel, A. and Meister, R.: Ten years experience with the five level avalanche danger scale and the GIS database in Switzerland, in: Proceedings International Snow Science Workshop, Jackson Hole, WY, 545-554, 2004.

Suter, C., Harvey, S., and Dürr, L.: mAvalanche - smart avalanche forecasting with smartphones, in: Proceedings International Snow Science Workshop, Squaw Valley, 630-635, 2010.

swisstopo: dhm $25{ }^{\circledR} 2015$ swisstopo (5704 000000$)$, reproduced by permission of swisstopo (JA100118), 2015.

Techel, F. and Pielmeier, C.: Automatic classification of manual snow profiles by snow structure, Nat. Hazards Earth Syst. Sci., 14, 779-787, doi:10.5194/nhess-14-779-2014, 2014.
Techel, F. and Winkler, K.: Fürchtet den Altschnee, Bergundsteigen, 90, 34-40, 2015.

Techel, F. and Zweifel, B.: Recreational avalanche accidents in Switzerland: trends and patterns with an emphasis on burial, rescue methods and avalanche danger, in: Proceedings International Snow Science Workshop 2013, Grenoble, France, 1106-1112, 2013.

Tillé, Y.: Sampling algorithms, in: Springer Series in Statistics, Springer, New York, doi:10.1007/0-387-34240-0, 2006.

Tillé, Y. and Matei, A.: sampling: Survey Sampling, r package version 2.5, available at: http://CRAN.R-project.org/package= sampling, last access: 5 June 2015, 2012.

Valt, M.: Incidenti da valanga sulle Alpi 1985-2009, Neve e Valanghe, 68, 14-23, 2009.

Winkler, K.: Entwicklung des Risikos bei Aktivitäten im freien Gelände, in: Proceedings Lawinen und Recht, 2015, Davos, Switzerland, in press, 2015.

Winkler, K. and Techel, F.: Users rating of the Swiss avalanche forecast, in: Proceedings International Snow Science Workshop 2014, Banff, Canada, 437-444, 2014.

Zweifel, B., Räz, A., and Stucki, T.: Avalanche risk for recreationists in backcountry and in off-piste area: surveying methods and pilot study at Davos, Switzerland, in: Proceedings International Snow Science Workshop 2006, Telluride, CO, 733-741, 2006. 